\title{
DA FLÂNERIE AO PROJETO DEMIÚRGICO DO SHOPPING CENTER
}

\author{
VALQUÍRIA PADILHA
}

R E S U M O Esse artigo analisa o atual projeto demiúrgico do shopping center a partir da história da sociedade de consumo, desde as práticas da flanerie na Paris do século XIX. Das suas origens nas lojas de departamento européias e sua rápida proliferação pelos Estados Unidos do pós-guerra, o shopping center é apreendido como "templo" onde ocorre uma entronização da mercadoria. Mais que um espaço para compras, tem se tornado um local de lazer reificado, do desejo de participar de um mundo de sonhos vendidos pela publicidade. É um local que exclui dele aqueles que não podem consumir e que também exclui, na sua lógica privada, a cidadania, o espaço público, a cidade e sua história.

P A L A V R A S - C H A V E Consumo; publicidade; shopping center; lazer; espaço público; espaço privado.

Em agosto de 2000 cerca de 150 moradores de favelas, desempregados e trabalhadores sem-teto organizados escolheram o Shopping Rio Sul, na zona sul da cidade do Rio de Janeiro, como local de um protesto contra a desigualdade social. $\mathrm{O}$ evento, até então inédito, chocou freqüentadores habituais e muitos lojistas que fecharam as suas portas com medo de assaltos e saques. Um dos organizadores do manifesto, André Fernandes, declarou à imprensa que tinham a intenção de "incomodar" e de "trazer um pouco de realidade para o centro do consumo". Com isso, pretendiam mostrar que, enquanto algumas pessoas privilegiadas consomem e desfrutam de seu "tempo livre" com segurança em lugares limpos, modernos e atraentes, existem milhares de pessoas vivendo em uma outra realidade, sob condiçōes distantes e até opostas a estas que reinam no universo onírico do shopping center.

Por que estes manifestantes escolheram um shopping center para seu protesto? Provavelmente, porque perceberam que este espaço acolhe calorosamente a racionalização do capital, tornando-se hoje templo de consumo onde os desejos, os projetos, as paixões e as relaçóes sociais materializam-se em objetos - e seus signos - a serem consumidos. O shopping center torna-se mais um locus urbano de distinção. Se não, como explicar o bloqueio aos mais pobres realizado de diferentes maneiras nos shopping centers? Como explicar que, nestes centros comerciais, as camadas privilegiadas da sociedade encontrem a segurança que não encontram mais nos espaços públicos? Isso só parece ser possível na medida em que o shopping center é um espaço privado que aciona seus mecanismos de segurança de forma a impedir a entrada e circulação de pessoas consideradas indesejadas e ameaçadoras da "ordem" artificialmente estabelecida.

Assim, o shopping center pode ser entendido como um espaço privado - que se propaga como público - criado para ser uma solução dos problemas da cidade onde reinam desajustes, desigualdades, contradições, imprevistos. Por isso, a cidade pode ser vista como o "mundo de fora" em contraposição ao shopping center, o "mundo de dentro". O "mundo de fora" é a "realidade real", o espaço urbano e seu caráter público. Esse mundo

1 Cf. "Sem-teto 'invade' shopping no Rio em protesto", O Estado de S. Paulo, 5.8.2000 (Geral). Interessante observar o verbo escolhido pelo jornalista responsável por esta matéria: "invadir", entrar à força ou hostilmente num espaço que não the pertence. 
contém uma outra realidade construída, o "mundo de dentro", asséptico e isento dos fatores imprevisíveis que agem no "mundo de fora". No shopping center tudo é estrategicamente programado, planejado, previsto.

A programação do espaço e da administração do shopping center por meio de uma "gerência científica" (Gaeta, 1992) visa o controle de uma nova cidade e uma nova forma de acumulação de capital. Segundo Santos Júnior, os shopping centers

concentram elementos que abrangem, de maneira sintética, desde a estruturação do espaço urbano do ponto de vista do capital, até a produção de imagens ligadas às representações ideológicas da sociedade. Espacialmente se apresentam como a linguagem da sedução materializada. (1992, p.61.)

Ao mesmo tempo em que a cidade real - ou o "mundo de fora" - desencadeia uma série de problemas para muitos, possibilita "alternativas" para poucos, como a criação do shopping center, a nova cidade do capital, a catedral onde uma parcela da população ido-

2 A Associação Brasileira de Shopping Centers (Abrasce) afirma que, no Brasil, o número de shopping centers vem praticamente dobrando a cada cinco anos. Em 1966 havia apenas um shopping center no Brasil, e em fevereiro de 2006, o país já contava com 263 em funcionamento, gerando 488.286 empregos. Cf. www.abrasce.com.br. Nos Estados Unidos, berço do nascimento do atual modelo de shopping center, em 1956 já havia cerca de 1.000 centros comerciais inaugurados e $2.000 \mathrm{em}$ construção. Segundo Rybczynski (1996), entre 1970 e 1990, a cada sete horas, em média, um novo shopping center era inaugurado nesse país.

3 A subordinação do lazer à lógica do capital dá-se basicamente pelas várias maneiras de mercantilização da diversão. Essa forma de mercadoria (que é produzida industrialmente, divulgada pela publicidade e trocada por dinheiro) que 0 lazer possui na sociedade capitalista de consumo tem sido a principal preocupacão dos estudos marxistas sobre o lazer. 0 lazer-mercadoria está no consumo dos bens materiais e simbólicos, como os produtos da indústria cultural, pacotes de viagem, brinquedos em parques de diversão, jogos eletrônicos, alimentação, cinema e diversão em shopping centers. latra as mercadorias e vivencia lazeres reificados. Mas, se a "catedral das mercadorias" faz sucesso hoje colocando o shopping center como um dos empreendimentos mais rentáveis e com maior taxa de crescimento em todo o mundo capitalista, ${ }^{2}$ é preciso ir às suas origens na constituição histórica do espaço urbano segundo a lógica do capital.

Como Engels já observou, por volta de 1845, quando escreveu $A$ situação da classe trabalhadora na Inglaterra, a ordem da produção industrial burguesa no capitalismo engendra uma desordem urbana que nos leva facilmente à conclusão de que o espaço urbano, com sua mistura entre ordem e caos, revela a própria essência da sociedade capitalista. A organização do espaço urbano exprime a organização social, de modo que a forma como as necessidades são satisfeitas (ou não) nas cidades torna-se um importante indicador de como estão sendo satisfeitas (ou não) todas as outras necessidades na sociedade. Dessa maneira, como lembra Lefebvre, "a existência urbana se confunde com a existência política, como a palavra indica. Se a cidade concentra o que faz uma sociedade, ela o distribui de uma maneira relativamente razoável em organizaçōes e instituiçōes” (2001, p.49).

A cidade - resultado da apropriação e transformação da natureza pelo homem - é, desde a decadência do feudalismo, o cenário onde o capitalismo protagoniza a acumulação de riqueza. No entanto, a urbanização capitalista vem provocando destruição irreversível da natureza na medida em que subordina o seu controle unicamente às exigências do lucro privado e da extração da mais-valia.

As reflexões até aqui apresentadas procuram evidenciar a importância de fazer um enlace teórico entre capitalismo, consumo e espaço urbano como base de uma análise crítica do shopping center como catedral das mercadorias e do lazer reificado. Então, é preciso entender que o shopping center nasce e se desenvolve como centro de consumo no seio da cidade capitalista de forma historicamente entrelaçada com a subordinação do lazer a essa lógica do capital. ${ }^{3}$

Hoje, os shopping centers refletem a "cultura de consumo" estadunidense, mas suas raízes históricas estão nas organizações espaciais e nas lojas de departamento da Europa do século XIX. Foi entre 1822 e 1832 que surgiram as primeiras galerias de Paris, impulsionadas pelo desenvolvimento das indústrias têxteis, pelo uso do ferro nas construções e pela utilização da fotografia como meio de comunicação. Eram grandes centros comerciais onde se vendiam mercadorias de luxo que, pela quantidade, podiam ser armazenadas em estoque e vendidas bem baratas em diversas promoções. Além disso, o comércio passa a ter a arte a seu serviço com o embelezamento das galerias. 
Benjamin nos oferece uma reflexão sobre esta época de modernização em Paris. Refere-se à Grande Exposição Internacional de 1867 como a fetichização ${ }^{4}$ total das mercadorias. Ele provoca:

As exposiçōes universais transfiguram o valor-de-troca das mercadorias. Criam uma moldura em que o valor-de-uso da mercadoria passa para segundo plano. Inanguram uma fantasmagoria a que o homem se entrega para se distrair. A indústria de diversōes facilita isso, elevando-o ao nível da mercadoria. $\mathrm{O}$ sujeito se entrega às suas manipulaçôes, desfrutando a sua própria alienação e a dos outros ... A fantasmagoria da cultura capitalista alcança o seu desdobramento mais brilhante na Exposição Universal de 1867. O Império está no apogeu do seu poder. Paris se afirma como a capital do luxo e da moda. (1991, p.35-6, grifos meus.)

Essa passagem é interessante para refletirmos como a "cultura de consumo", que se instalou no Ocidente a partir do final do século XIX, torna-se reflexo da racionalidade do capitalismo quando realiza a passagem do ato de comprar objetos úteis ao ato que consubstancia o prazer de comprar. A "cultura de consumo" que se estabelece transforma os hábitos cotidianos, as relações entre as pessoas, as percepções dos espaços e os significados dos objetos. ${ }^{5}$

Parece-me bastante pertinente destacar a provocação feita por Benjamin (1991) sobre as transformações de Paris no século XIX visto que ele percebe que ali o capitalismo já começa a configurar-se como uma cultura de reificação, que faz com que o valor-de-uso das mercadorias seja subordinado a seu valor-de-troca. E mais: o autor percebe que a alienação humana que provém desse processo de fetichização implica a entrega das pessoas à "cultura de consumo" como uma forma de divertimento e de felicidade.

Diante de todas as transformações que foram moldando a cultura urbana, Sennett (1998) vê um importante paradoxo no final do século XIX: as condições materiais tornaramse mais conhecidas e mais regulares para as pessoas enquanto a vida pública foi ficando cada vez mais instável. Mas a vida pública responde à nova vida material alterando o comércio varejista nas capitais. As novas lojas de departamentos são uma forma de intercâmbio entre o público e o privado nas vidas das pessoas. De certa forma, o consumo e o desenvolvimento da comunicação provocam mudanças radicais nos limites da vida pública e da vida privada.

As lojas de departamentos que nasciam e marcavam a época eram uma resposta à produção fabril, que possibilitava abaixar os preços de algumas mercadorias ao mesmo tempo em que as diversificava. E como a produção era feita em massa, havia a necessidade de formar-se também uma massa de consumidores, o que não era possível acontecer no comércio tradicional das ruas parisienses.

Com as novas lojas de departamentos nas capitais, até as pessoas da classe média e os trabalhadores podiam comprar artigos que antes nem sonhavam em ter. $\mathrm{Na}$ verdade, esta nova forma de comércio provoca o consumo de coisas supérfluas, o que dava aos compradores a sensação de estar participando dessa padronização das mercadorias. Mas os lojistas tinham diante de si um novo desafio: motivar as pessoas a comprar mercadorias das mais variadas e das mais indefinidas. O curioso é notar que, para resolver este problema, os comerciantes inventaram espetáculos do lado de fora das lojas para "dotar as mercadorias, por associação, de um interesse que a mercadoria poderia intrinsecamente não ter" (Sennett, 1998, p.182). Além desse importante recurso, as lojas de departamentos deveriam sempre manter uma oferta de utensílios diferentes, e um empurrava o comprador ao outro, na medida em que deveriam estar dispostos lado a lado.
4 Fetichização é um conceito que deriva da palavra fetiche, que, por sua vez, deriva da palavra portuguesa feitico. Seu uso está ligado à idéia de que, no capitalismo, as mercadorias ganham um sentido que ultrapassa a sua simples utilidade. As mercadorias são revestidas de uma magia, de uma fantasmagoria ou um feitiço, ganhando sig nificados e valores que passam a ser atrelados a elas, como felicidade, prazer, sucesso, modernidade etc. A moda é um bom exemplo da fetichização das roupas e calçados. Esses bens passam a ter valor pelo status ou pela marca social mais do que pela utilidade de proteger o corpo do frio ou simplesmente de cobri-lo.

5 Sennett (1998) entende a formação dessa "cultura de consumo" numa análise histórica do declínio da esfera pública associado ao aumento da importância do privado. 0 autor associa 0 fim da cultura pública ao desenvolvimento do capitalismo nos séculos XVIII e XIX. 0 capitalismo impulsionou um deslocamento do foco das pessoas para as coisas, fazendo com que as pessoas busquem significados pessoais em objetos e em condições objetivas da vida em sociedade. E o crescimento das cidades foi o cenário dessa mudança de es tado público para estado privado da sociedade ocidental na passagem do século XIX para o século XX. 
60 Barão Georges-Eugène Haussmann, por volta de 1850 , foi indicado por $\mathrm{Na}-$ poleão para ocupar o cargo de chefe de departamento do Sena, em Paris. Ele acumulava os cargos de prefeito, ministro de obras públicas e planejador-chefe da cidade. Haussmann realizou uma verdadeira reconstrução de Paris, o que Sennett (1998) chamou de "ecologia de classes", na medida em que ele buscava uma unidade econômica homogênea para os bairros da cidade. Ele próprio se identificava como um "artiste démolisseur" (artista demolidor), pois destruía Paris com a intenção de criar uma nova cidade, mas com ares de obra de arte.

7 Podemos entender que, segundo Baudelaire, o ocioso flâneur era sinônimo de protesto contra a divisão do trabalho, a operosidade e a eficiência que a industrialização reclamava. Muitas vezes o flâneur levava consigo, nas suas caminhadas, tartarugas para Ihe ditarem o ritmo dos passos. Eles pretendiam, de certa forma, mostrar a velocidade com que 0 progresso deveria acontecer. Assim, o flâneur é visto como uma figura transgressora que não se submete à ditadura dos horários ou aos deveres do consumidor, na medida em que ele não vai às compras e que apenas perambula pelas passagens dos comércios.
No momento de olhar as mercadorias e comprá-las, suspendia-se o caráter de utilidade dos objetos para dar espaço ao prazer de comprar algo inesperado, diferente. Os varejistas perceberam então que deveriam provocar nos consumidores o desejo de comprar objetos exóticos e cheios de novidade. Na verdade, como sugere Sennett (1998), era preciso criar nas lojas de departamentos uma desorientação como forma de estímulo às compras. Essa desorientação foi tomando corpo com a propaganda, que se baseia na superposição de imagens. Era necessário revestir as mercadorias de mistérios.

As atenções dos consumidores não estavam mais sobre as condições em que os objetos eram feitos, mas passaram para os objetos em si, na medida em que são atribuídos novos sentidos e novos mistérios que desviam os compradores da utilidade das mercadorias que compram. As vitrines das lojas e as fotografias publicitárias que criavam ambientes fantasiosos ou colocavam figuras públicas importantes usando tal ou qual mercadoria criavam uma associação entre os artigos das lojas e o status incorporado neles.

A personalidade das pessoas que consumiam as mercadorias porque estavam muito bem dispostas em vitrines ou porque estavam associadas a uma duquesa qualquer, na verdade, estava sendo moldada por essa nova concepção de consumo. Era crescente a importância que os cidadãos londrinos ou parisienses davam às aparências exteriores ou à aquisição de certos bens como sinais de caráter pessoal ou de status social. Era o valor simbólico das mercadorias que movia, cada vez mais, os consumidores às compras.

As galerias de Paris, que foram descritas por Benjamin (1991) e por Sennett (1998), tornaram-se o centro de consumo e de luxo, configurando-se em espaços de ostentação e de desejo de consumo. As vitrines e a disposição das lojas em corredores distribuídos em forma de labirinto possibilitaram a flanerie, ou seja, o ato de passear, olhando vitrines, sem objetivo definido. O flâneur é aquele passante que busca uma identidade para si através do olhar. Charles Baudelaire é o escritor francês do século XIX que cria o flâneur como personagem para explicar a modernidade que surgia. Na sua literatura panorâmica - com base no hábito do escritor de ficar observando o seu entorno como a um panorama - Baudelaire (1997) faz ressaltar que antes de Haussmann, ${ }^{6}$ eram raras as oportunidades de se praticar a flânerie, já que não existiam passagens largas para os transeuntes. Por isso as galerias eram o lugar preferido dos flâneurs, perambuladores e fumantes. Assim, a rua torna-se moradia para o flâneur que acaba por legitimar, por isso, a sua vagabundagem. ${ }^{7}$

O que estava sendo criticado pela literatura baudelairiana, por meio da figura do flâneur, era o efeito narcotizante da cidade grande sobre a multidão de seus habitantes. $\mathrm{Na}$ época do crescimento urbano e desenvolvimento tecnológico, vários intelectuais, artistas e escritores refletiam em suas obras os efeitos provocados pela vida na cidade grande, como o crescimento populacional, a indiferença entre as pessoas, a falta de espaço que as obriga a apertarem-se em determinados lugares, a perda do contato pelo olhar e pelas palavras entre as pessoas. Na verdade, tratava-se de fazer a crítica à coisificação à qual se sujeitavam as pessoas que vivenciavam aquela fase do despertar do capitalismo urbano. Por isso a flânerie é tão importante nas reflexões sobre todo o processo de transformação por qual passavam as capitais francesa e londrina.

\section{FETICHISMO DA MERCADORIA: ELEMENTOS PARA A CRÍTICA À SOCIEDADE DE CONSUMO}

Essa viagem ao século XIX leva a pensar que o fetichismo consumista presente nos shopping centers e na publicidade dos dias atuais originou-se nesta fase do desenvolvimento 
do capitalismo em que se combinaram produção em massa por meio da indústria e crescimento do mercado urbano com as lojas de departamentos e galerias. O fetichismo - revestimento dos objetos para venda com valores ideológicos - era o fenômeno intrínseco às primeiras lojas de departamentos. As compras passaram a ser prazerosas para os ricos, que foram deixando de mandar seus empregados fazê-las ou aguardar a presença dos mercadores em suas residências. O consumo de mercadorias começa, então, a significar um mergulho em fantasias e status social, na medida em que os objetos passaram a ser adquiridos não pelo seu valor-de-uso, mas pelo significado social de sua posse.

Nesse processo de distinção social pela posse, a aparência das mercadorias - seu aspecto estético - ganha cada vez mais importância. Vale a pena citar uma longa passagem de Haug, quando afirma que

... na relação de interesses da troca, a tendência para a tecnocracia da sensualidade situa-se economicamente na subordinação do valor de uso ao valor de troca. Uma vez que, com o desdobramento da produção privada de mercadorias, produz-se essencialmente valores de troca e não "meios de sobrevivência" essencialmente sociais - meios para a satisfação de necessidades -; uma vez que as qualidades das mercadorias, que correspondem às necessidades dos futuros consumidores, não passam, portanto, de um meio para atingir um fim - a realização do valor de troca -, vale o que o jovem Marx acentuou com veemência nos $M a$ nuscritos parisienses: todo produto de uma produção privada "é uma isca, com a qual se pretende atrair a essência do outro, seu dinheiro”, a única coisa importante para o ponto de vista do valor de troca. Por outro lado, "toda necessidade real ou possível" do homem sensível "significa uma fraqueza que levará a mosca à armadilha". Onde quer que haja carência, necessidade e precisão, surge um proprietário de mercadorias oferecendo os seus "amáveis préstimos" através de "amabilíssimas aparências", para logo em seguida apresentar a conta. (1997, p.27.)

A aparência das mercadorias é, na verdade, "um valor-de-uso estético prometido pela mercadoria" como forma de se obter dinheiro (Haug, 1997). Desse modo, o aspecto sensível torna-se portador de uma função econômica e "quem domina a manifestação, domina as pessoas fascinadas mediante os sentidos” (Haug, 1997, p.27). Na análise desse autor, quem busca o amor faz-se bonito e amável. Da mesma maneira, as pessoas retiram a sua expressão estética das mercadorias, as quais, por sua vez, retiram a sua linguagem estética e sensível do galanteio amoroso entre os seres humanos.

O valor-de-troca, um forte estímulo estético e a libido são moldados fazendo com que os meios de expressão (como a publicidade) se tornem valiosos e caros. O valor-deuso das mercadorias - sua utilidade intrínseca - passa a se submeter ao valor-de-troca. Assim, a aparência das mercadorias passa a ser de fundamental importância para sua venda. É a publicidade que vai garantir a divulgação da aparência criada, no capitalismo, à imagem da ansiedade do público consumidor.

O fetichismo da mercadoria e o controle que o capital exerce sobre o trabalho humano, no capitalismo, são causas diretas da alienação ou estranhamento dos trabalhadores. Marx desenvolve esta análise nos Manuscritos econômico-filosóficos de 1844. Ao produzir mercadorias, o trabalhador torna-se, ele mesmo, uma mercadoria - vende sua força-de-trabalho no mercado como se fosse uma mercadoria qualquer. "Com a valorização do mundo das coisas aumenta em proporção direta a desvalorização do mundo dos homens" (Marx, 1989b, p.148, grifos do autor). O produto do trabalho - o objeto - 
aparece, no final, como algo alheio ou estranho ao trabalhador, como um objeto que não lhe pertence.

Nas sociedades capitalistas, o homem não produz mais apenas para satisfazer suas necessidades diretas, embora a produção seja a objetivação das necessidades humanas, em certa medida. Existem outras necessidades em jogo que são as necessidades de valorização do capital. A produção capitalista é baseada num trabalho excedente que gera mais-valia (na produção das mercadorias) e lucro (na venda das mercadorias). Este excedente não é calculado com base nas necessidades do homem, mas sim com base nas necessidades do capital, o qual, por sua vez, precisa criar novas necessidades para estimular a demanda e o consumo não só de mercadorias com valores-de-uso mas, também, com seus respectivos valores-de-troca.

Como bem nos lembra Istvan Mészáros,

o capital não trata valor-de-uso (que corresponde diretamente à necessidade) e valor-de-troca meramente como dimensões separadas, mas de uma maneira que subordina radicalmente o primeiro ao último. Devidamente situado no tempo e no espaço, isto representa uma inovação radical, que abre horizontes anteriormente inimagináveis para o desenvolvimento econômico. Uma inovação baseada na constatação prática de que qualquer mercadoria pode estar constantemente em uso, num extremo da escala, ou ainda nunca ser usada, no outro extremo das possíveis taxas de uso, sem perder por isso sua utilidade no que tange às exigências expansionistas do modo de produção capitalista. (1989, p.22-3.)

Partindo, então, deste princípio do capital que trata útil e utilidade em termos de vendabilidade, quanto menos tempo uma dada mercadoria é realmente usada melhor é do ponto de vista do capital, uma vez que aumenta a vendabilidade ou a troca de uma mercadoria por outra. Para haver reprodução do capital, a produção deve visar um consumo descartável, do desperdício. A única coisa que realmente importa ao capital é que as mercadorias produzidas possibilitem a realização do seu valor-de-troca, independente do seu valor-de-uso.

Nesse sentido, o capitalismo é um sistema que precisa sempre aumentar a produção de mercadorias em quantidade e variedade, mas não em qualidade ou durabilidade. Por isso, independentemente da forma como se dá esta produção - se ela é artesanal, mecânica ou automatizada -, sob a lógica do capital ela não está mais ligada diretamente às necessidades humanas. Quando os meios de produção tornam-se capital,

... eles têm de se opor às necessidades humanas, se a lógica do capital o exige, sobrepondo às necessidades humanas existentes e potencialmente emergentes as assim chamadas "necessidades da produção", que correspondem diretamente ao interesse de salvaguardar a expansão do capital. (Mészàros, 1989, p.29, grifos do autor.)

As exigências produtivas do capitalismo que visam a auto-realização e a expansão do capital transformam as necessidades humanas em necessidades alienadas, na medida em que as artificializa. Em vista disso, apesar do crescente (e contraditório) aumento da produtividade, torna-se ilusório o sonho de uma sociedade da abundância cada vez maior. Em princípio, segundo Mészáros (1989), é verdade que o desenvolvimento da produção capitalista requer a expansão do círculo de consumo, como acontece com o círculo da produção. No entanto, o capital percebe que pode ser muito mais interessante acelerar a 
velocidade de circulação dentro do próprio círculo de consumo em vez de correr riscos alargando este círculo.

Assim, enquanto a "taxa de uso decrescente" pode aumentar a lucratividade, não há razão para ampliar a circulação, muito pelo contrário, há uma "restrição artificial" desse círculo de consumo, do qual são excluídos vastos segmentos da população, não só em países do terceiro mundo como até mesmo em países "avançados" (Mészáros, 1989). Seguindo esse raciocínio, parece ser evidente a impossibilidade de uma sociedade de abundância para todos, não apenas pelos limites ambientais, mas pela própria lógica interna do capital. No entanto, é preciso, para a reprodução do capital, estimular a abundância da sociedade do consumo, mesmo que ela fique apenas na ilusão. E a publicidade se encarrega da condução desse estímulo.

\section{PUBLICIDADE E OBSOLESCÊNCIA PLANEJADA DE MERCADORIAS}

A origem da palavra publicidade está associada à noção de público na acepção de manifestaçōes acessíveis a todos, ou seja, a publicidade tem a tarefa de tornar algo público. A publicidade e o marketing invadem, então, a esfera pública. A partir da segunda metade do século XIX, a publicidade ganha real importância no processo capitalista de concentração industrial e passa, ela própria, a se beneficiar dos avanços dos estudos de mercado. No século XX a publicidade televisiva ganha um estatuto preponderante, já que a imprensa escrita se restringe às camadas superiores da população, enquanto a televisão atinge todas as camadas sociais. A publicidade passa a atuar diretamente sobre os indivíduos como consumidores, manipulando-os comercialmente sob o pretexto de responder aos interesses do bem comum. Assim, a publicidade, a serviço dos capitalistas, tem a tarefa de criar o novo, novos arquétipos ou símbolos que o público deve adotar. Conforme sugere Habermas (1992), a publicidade confere a seu objeto a dignidade de um negócio de interesse público e é sobre esse objeto que as pessoas privadas formam sua opinião pública.

Fromm tem uma passagem interessante que sintetiza essa lógica consumista por trás da publicidade:

Se o princípio econômico dominante é o de que produzamos cada vez mais, o consumidor deve estar preparado para querer - isto é, para consumir - cada vez mais. A indístria não depende dos desejos espontaneos do consumidor de quantidade cada vez maior de mercadorias. Fabricando objetos que devem cair em desuso, ela o força a comprar coisas novas quando as velhas poderiam durar muito mais. ([19--], p.52, grifos meus.)

Retomando o princípio econômico da "obsolescência planejada", a publicidade é mais uma ferramenta de criar necessidades nas pessoas para que a circulação de mercadorias tenha um fluxo otimizado. Por isso, pode-se afirmar que ela visa muito mais do que o corpo: seu alvo é a "alma humana”. Como sugere Barber (1996), o corpo tem limites físicos de satisfação que a alma não tem, o que faz com seus desejos sejam infinitos. Assim, o espírito humano é o verdadeiro motor da "sociedade de consumo", mais do que o corpo. Na verdade, os profissionais da publicidade e do marketing procuram descobrir os desejos mais inconscientes dos seres humanos, aquilo que é uma necessidade no plano subjetivo e não no plano da objetividade. Foi por esse caminho que as agências de publi- 
80 Parque Dom Pedro Shopping, inaugurado em Campinas (SP), em 2002, é um shopping center que se propaga como um investimento imobiliário que preserva 0 meio-ambiente. Uma "homenagem à natureza" é prestada por esse shopping, um espaço dividido em setores denominados "Flores", "Águas", "Árvores", "Colinas" e "Pedras". O Parque Dom Pedro Shopping é considerado um megaempreendimento onde foram investidos mais de duzentos milhões de reais e é, hoje, o maior centro de moda, cultura e lazer da América Latina. Possui a maior praça de alimentação do Brasil, comporta mais de 360 lojas, 15 salas de cinema e ainda tem uma capela. 0 Parque Dom Pedro Shopping orgulha-se por ter plantado mais de 25 mil mudas de árvores nativas ao redor do centro comercial, mas não contabiliza quantas árvores precisou derrubar para ser construído. "O modelo pioneiro do Parque D. Pedro está aliado ao bem-estar e entretenimento da comunidade local e à preocupação especial com o meio-ambiente." Disponível em www.parquedpedro.com.br. Quando a home page do Parque Dom Pedro Shopping é acessada, ouvese som de pássaros cantando.

9 É interessante observar que os shopping centers construídos nas décadas de 1960 e 1970 ainda possuem um estilo arquitetônico de linhas mais retas, com ambiente mais sombrio, sem nenhuma luminosidade natural ou percepção, por parte dos consumidores, das condições climáticas externas. cidade descobriram que é quase sempre muito vantajoso estabelecer uma correlação entre desejo sexual e desejo de compra.

Num estranho processo de personalização imposto pelo sistema de consumo, existe um efeito semelhante ao processo de "naturalização". Baudrillard (1995) exemplifica: desmata-se uma floresta para ali construir um condomínio chamado "Cidade Verde", onde serão replantadas árvores para dar sugestão de espaço de natureza. ${ }^{8} \mathrm{Ou}$ ainda, vende-se uma maquiagem com o argumento de que ela deixará a pele com um brilho natural e duradouro. $\mathrm{O}$ mesmo pode-se dizer dos shopping centers, construções totalmente caracterizadas por espaços fechados e cobertos, ventilados e iluminados artificialmente. A imensa maioria desses centros comerciais conta com uma ou mais praças, fontes, esculturas, plantas, flores ou árvores que são ornamentos fundamentais de sua decoração. $\mathrm{O}$ consumidor imerso neste mundo artificial não fica totalmente privado de algum contato com a natureza ou com a imagem das ruas e praças do mundo que ele deixou para fora. Em vários shopping centers, cujas construções são mais modernas, é possível observar passagens ou praças cobertas com teto de vidro para que o visitante possa, ao menos por alguns minutos, perceber a luz "natural" do dia. ${ }^{9}$

Godelier (1977, p.213) ressalta que o fetichismo do mundo das mercadorias consiste na propriedade que o valor tem de dissimular a sua essência. Assim, não é o homem que se engana sobre a realidade, mas sim a realidade que o engana aparecendo sob uma forma que a dissimula e a apresenta contrária à consciência espontânea dos indivíduos. Esses indivíduos criam representações sobre suas relações econômicas, formando crenças ilusórias e fantasmagóricas sobre a realidade social. Godelier (1977) afirma que essas representações ilusórias não podem ser o ponto de partida da análise científica da realidade social.

Hoje, o que mais caracteriza a publicidade é o fato de ela vender idéias, valores, estereótipos e preconceitos. Os produtos anunciados são carregados de significados e de possibilidades e as emoções são muito mais exploradas que a utilidade do produto propriamente dita. A publicidade faz um serviço de depuração, de limpeza das coisas, pois ela mantém apenas o lado positivo do que anuncia. Os anúncios publicitários divulgam apenas a dimensão do que é bom nos produtos, quando, na realidade, sabemos que as mercadorias e os serviços também trazem consigo problemas, defeitos, contradiçôes. Assim, a publicidade elimina aquilo que há de vida, que é real, que é da natureza das coisas. A recusa dessa dimensão nos objetos e atividades anunciadas torna o mundo falsamente harmonioso.

Na medida em que a publicidade e a "cultura de consumo" atuam nas sociedades capitalistas como instrumentos que conformam a arte, a cultura, as necessidades e a própria vida e, na medida em que legitimam a conversão de tudo em mercadoria, elas contribuem para a generalização do processo de reificação ou coisificação.

\section{LAZER-MERCADORIA NO SHOPPING CENTER}

Nesse sentido, o lazer - como atividade a ser realizada num tempo considerado disponível ou "livre" - também é mercadoria nas sociedades regidas pela lógica e racionalidade do capital. Por isso, tempo livre e capitalismo formam um par imperfeito (Padilha, 2000), do ponto de vista do caráter de liberdade atribuído a esse tempo.

Em geral, as abordagens críticas do lazer - de inspiração marxista - visam entendêlo como um fenômeno social que, por estar inserido numa sociedade contraditória, é, ele também, cheio de contradições. Assim, o lazer é um tempo que serve tanto para o consumo manipulado pela publicidade que prioriza o lucro dos capitalistas como para a pos- 
sibilidade de transformar-se em tempo de reflexão e praxis. No "shopping center híbrido" - que hoje perdeu o caráter exclusivo de centro de compras para se transformar num centro de lazer e de serviços - prevalece um certo encantamento das pessoas que ali ocupam o seu tempo supostamente livre de forma a configurar um lazer reificado.

A tese que procuro defender quanto à relação entre shopping center, consumo e lazer é a de que os shopping centers são símbolos de uma sociedade que valoriza o espetáculo do consumo de bens materiais e de lazer-mercadoria; e que, além disso, oferecem a uma parcela da população o direito a esse consumo e a esse lazer, enquanto exclui a maioria dessa mesma população. Assim, esses centros comerciais configuram-se como espaços de lazer alienado, influenciando de forma decisiva a construção da identidade social de cada um, tanto dos que freqüentam esses espaços como também dos que não os freqüentam, mas, enfeitiçados pela publicidade e pela "cultura de consumo", desejam freqüentá-lo.

O shopping center pode ser entendido como um "não-lugar" (Augé, 1994) onde é muito difícil que as pessoas travem relaçôes sociais entre si que não sejam coisificadas ou permeadas por objetos de consumo. A sociabilidade dos freqüentadores de shopping centers é, portanto, estranhada e reificada, na medida em que "o vínculo social entre os indivíduos assume, então, a forma de coisa" (Silveira, 1989, p.55). Os "sujeitos coisificados" são determinados e limitados pelas coisas que se apropriaram do que era próprio do sujeito. ${ }^{10}$ Assim, a coisa, o capital, a mercadoria, o dinheiro dependem dos sujeitos para reproduzirem-se como tais. Esse estranhamento realiza-se plenamente na complexa engrenagem do shopping center, como este texto procura asseverar.

Entre as mercadorias presentes no shopping center está o lazer: as salas de cinema, os jogos eletrônicos, a praça de alimentação, os ocasionais e padronizados eventos artísticos, os brinquedos, entre outros. Os diversos equipamentos de lazer disponíveis em shopping centers levam seus freqüentadores a encontrarem diversão em torno da celebração do objeto, de modo que, mesmo no lazer, o ser permanece subjugado ao ter. O lazer oferecido em shopping centers é alienante porque leva ao distanciamento dos sujeitos deles próprios ao mesmo tempo que os "empobrece". Esse empobrecimento deve ser entendido em relação ao que Marx considerava como a verdadeira riqueza, ou seja, “... o homem (na) plena riqueza de seu ser, (é) o homem rico e profundamente dotado de todos os seus sentidos ..." (Silveira, 1989, p.48, grifos do autor). O homem rico, para Marx, não tem a riqueza na sua conotação burguesa, mas é o homem emancipado que realiza plenamente seus sentidos. ${ }^{11} \mathrm{~A}$ perversa lógica na qual está inserido o shopping center não possibilita que o homem desenvolva esta dimensão da riqueza.

Ainda é possível pensar que o shopping center é uma instituição que privatiza o lazer. Mas é preciso reconhecer que isso acontece e complexifica-se na medida em que não existem políticas públicas que confiram ao fenômeno do lazer o caráter de direito social, direito de todos. O shopping center só vem aumentando sua participação na esfera do lazer urbano por causa da brecha que a inexistência ou ineficiência dos espaços públicos de lazer, sobretudo no Brasil, vêm abrindo. A ausência de políticas públicas favorece não só a privatização do lazer pelo shopping center como também a segregação social, uma vez que o poder aquisitivo acaba sendo um dos determinantes principais para as tomadas de decisões diante das escolhas existentes.

Por isso, é necessário relativizar e analisar criticamente a crença e valorização da "escolha" e da "liberdade" como principais atributos do lazer. De modo geral, prevalece a idéia equivocada de que o lazer está sempre imune às formas de não-liberdade, de opressão, de alienação, como se ele integrasse um mundo independente de toda a racionalidade

10 Sobre estranhamento e os sujeitos sujeitados pelas "coisas", Paulo Silveira afirma: "Como coisa a natureza não é objeto para o homem, no sentido de que não resulta da atividade prática de um sujeito. Por conseguinte, mesmo sendo constituída como coisa na história, isto é, pelo homem, ela é evidenciada praticamente de uma forma abstrata, como se fosse dotada de poder e de autonomia próprios (esta é precisamente uma das dimensões do estranhamento). E, paradoxalmente, é como se a coisa encarnada nas diversas formas em que é capaz de metamorfosear-se, em capital, em valor-de-troca, em mercadoria, em dinheiro, é que pusesse sujeitos: os sujeitos como postos pela coisa, isto é, sujeitados" (Silveira, 1989 , p.47, grifos do autor).

11 "Mas, de fato, se se despoja a riqueza de sua limitada forma burguesa, que é a riqueza senão a universalidade das necessidades, capacidades, gozos, forças produtivas, etc., dos indivíduos, criada no intercâmbio universal? Que senão o desenvolvimento pleno do domínio humano sobre as forças naturais, tanto sobre as da assim chamada natureza como sobre sua própria natureza? ... Que senão uma elaboração como resultado da qual o homem não se reproduz em seu caráter determinado, mas que produz sua plenitude total?" (Marx apud Silveira, 1989, p.49). 
do capital. Embora as pessoas possam realmente ter a sensação de que são mais livres e de que têm mais poder de escolha nos momentos de lazer, esses atributos precisam ser, parafraseando Benjamin (1994), "escovados a contrapelo", superando as aparências e buscando a essência dos fenômenos.

Está na própria origem da palavra lazer - do latim licere - o significado de "ser permitido", que pode alimentar uma visão restrita de liberdade, como na afirmação de Freitas: "Hoje, para encontrar liberdade, é preciso procurar espaços onde o lazer esteja protegido, fora de perigo, como propóem os shopping centers" (1999, p.135, grifos meus). Que perigo seria este do qual as pessoas se vêem protegidas ao desfrutar dos lazeres oferecidos pelos shopping centers? Provavelmente, o perigo que brota das desigualdades sociais estampadas na dinâmica da vida real, do "mundo de fora" ao qual o shopping center não pode pertencer sob pena de perder seus maiores atrativos.

\section{SHOPPING CENTER COMO ESPAÇO DE SEMIFORMAÇÃO E DE CULTURA DESCARTÁVEL}

12 A teoria da semicultura é complexa e densa em Adorno (1996). Ele entende semicultura como semiformação. A idéia de formação cultural implica uma humanidade sem exploração, de homens livres numa sociedade livre. Formação é "a libertação da imposição dos meios e da estúpida e mesquinha utilidade" (p.392) e tem como condições a autonomia e a liberdade. Nesse sentido, semiformação ou semicultura passa a significar o ajustamento do conteúdo da formação (cultura + filosofia) pelos mecanismos de mercado à consciência da massa, dos excluídos do privilégio da cultura. Para Adorno, uma das principais figuras que socializa esse ajustamento dos conteúdos da formação pelos mecanismos do mercado para as massas é o publicitário. A semicultura é o espírito da indústria cultural e é sinal de conformismo. Adorno defendia a necessidade de um resgate da "formação cultural tradicional" (p.395) para servir de antítese à semiformação, que é uma forma de necrose da formação cultural. Para Adorno, a formação foi esmagada pela queda do pensamento filosófico. "O semiculto dedica-se à conservação de si mesmo sem si mesmo" (p.405).
Partindo dessas reflexões, pode-se fazer um paralelo entre os shopping centers de hoje e as grandes Exposições Universais do século XIX que ocorriam em Paris: ambos são espaços de "fantasmagoria a que o homem se entrega para se distrair" (Benjamin, 1991, p.53). Esses espaços, ao distrair as pessoas de forma estranhada, promovem a comercialização de seus desejos, de seus prazeres e, também, de seu "tempo livre". Nos shopping centers, a experiência de diversão e descanso passa pelo consumo real ou visual de bens materiais, de bens da "indústria cultural", em particular o cinema hollywoodiano que propaga o "American way of life", transformando o "tempo livre" das pessoas em tempo estranhado.

Espaços como o shopping center afastam as pessoas de qualquer experiência de "formação", nos termos de Adorno (1996); ou seja, a "formação" deveria corresponder a uma sociedade de seres livres e iguais. Ela deveria dizer respeito ao "indivíduo livre e radicado em sua própria consciência, ainda que não tivesse deixado de atuar na sociedade e sublimasse seus impulsos" (Adorno, 1996, p.392). Essa "formação", que é cultural, segundo Adorno, supõe uma "humanidade sem exploração" e, mais do que isso, supõe a libertação da imposição dos meios e da utilidade, o que significa a autonomia do ser social. Nesse sentido, o shopping center, por toda a sua complexidade, dificulta ainda mais o fim do que Adorno (1996) chamou de "necrose da formação cultural" - ou a "semicultura". ${ }^{12}$ Este espaço urbano de consumo e de lazer é como a "indústria cultural": leva as pessoas à ilusão de que "todos os que riem juntos conseguem a identificação" (Adorno, 1996, p.396).

No shopping center híbrido, é evidente a ausência de uma totalidade reconciliada com os singulares autônomos, assim como sob a lógica do capital, em geral. Neste espaço, os sujeitos estão ainda mais destituídos de liberdade de forma que, como sugere Adorno (1996), a vida em conjunto com os outros não se articula como verdadeira, uma vez que lhe falta o necessário apoio em si mesma. A consciência crítica não existe na "semiformação" cultural, uma vez que ela é "o espírito conquistado pelo caráter de fetiche da mercadoria” (Adorno, 1996, p.400).

A mesma análise que a Teoria Crítica desenvolveu em relação à "indústria cultural" pode ser feita em relação ao shopping center híbrido. A "indústria cultural" colabora para a "semiformação cultural", na medida em que, como sugere Adorno (1996), os motivos do lucro encobrem a cultura como um mofo. A "indústria cultural”, assim como o shopping 
center, incentiva a necessidade por "semicultura", da qual se nutre o mercado. O consumo dos produtos da "indústria cultural" - e do shopping center - está intimamente ligado a um tipo de narcisismo coletivo que faz com que exista uma identificação coletiva que, de certa forma, compensa a sensação de culpa por não fazermos o que deveria ser feito.

Diante de tudo o que foi colocado aqui, podemos sustentar que o shopping center é um espaço de "semiformação cultural" que oferece uma "cultura descartável" (Fontenelle, 2002) e um lazer reificado ao mesmo tempo que representa uma afirmação da racionalidade econômica do capital no interior da sociedade. $\mathrm{O}$ shopping center pode servir, então, como uma referência para pensar não só a sociedade capitalista em geral como também a "sociedade de consumo" e de lazer, vista como um "mundo encantado" que, num delírio coletivo, obscurece a consciência dos seres sociais.

O shopping center é, assim, o locus do estranhamento, do sujeito "semiformado", da reificação do prazer e do lazer. O homem não está alienado e estranhado apenas do e no trabalho que realiza (tanto em relação ao produto do trabalho quanto em relação à atividade mesma da produção), mas também do e no lazer, do e no tempo disponível. Numa perspectiva ontológica, pode-se pensar que a mesma lógica que aliena do homem, em seu trabalho, a sua própria natureza, ou seja, aliena o gênero humano (Marx, 1983), não cessa de agir quando o homem está fora do trabalho.

Entre as possibilidades de ocupação desse tempo disponível do homem (principalmente os das classes burguesas) está a busca por segurança, beleza, distração, alegria e lazer em shopping centers. No entanto, nestes templos de consumo e de lazer os homens continuam sob as condições de alienação e de estranhamento nas quais se encontram no "mundo de fora", em outras palavras, nos shopping centers, os seres sociais estão alienados de si mesmos. Eles continuam alheios ao seu ser genérico, o que se agrava ainda mais quando se percebe que seu comportamento e suas relações com o mundo são mediatizados prioritariamente por objetos, por coisas. Nos shopping centers, até mesmo o lazer torna-se algo a possuir, a consumir, a usar e a gastar. Não há nem espaço nem tempo para a espontânea e desinteressada criação de lazer.

No shopping center, os indivíduos não conseguem independência das finalidades exteriores, ou seja, eles permanecem aprisionados no reino da necessidade, quando o lazer e a arte devem pertencer ao reino da liberdade. Mas, é preciso atentar para o fato de que a plena liberdade em um reino supõe a liberdade em outro. Nesse sentido, valho-me das instigantes palavras de Antunes:

Como o sistema global do capital dos nossos dias abrange também as esferas da vida fora do trabalho, a desfetichização da sociedade do consumo tem como corolário imprescindível a desfetichização no modo de produção das coisas. O que torna a sua conquista muito mais difícil, se não se inter-relaciona decisivamente a ação pelo tempo livre com a luta contra a lógica do capital e a vigência do trabalho abstrato. Do contrário, acaba-se fazendo ou uma reivindicaçãoo subordinada à Ordem, onde se crê na possibilidade de obtê-la pela via do consenso e da interação, sem tocar nos fundamentos do sistema, sem ferir os interesses do capital ou, o que é ainda pior, acaba-se gradativamente por se abandonar as formas de ação contra o capital e de seu sistema de metabolismo social, numa práxis social resignada. (1999, p.176, grifos do autor.)

Como afirmou Marx, se no capitalismo "o trabalhador decai a uma mercadoria" e "se torna tão mais pobre quanto mais riqueza produz", a partir de um olhar crítico - que desconfia da autoridade dos fatos - lançado para o shopping center é possível pensar que 
quanto mais poderes o homem confere às mercadorias e ao lazer coisificado, mais ele torna-se alheio a si mesmo e, conseqüentemente, aos outros seres sociais.

Os shopping centers são considerados neste texto como lugares de consumo que oferecem estrategicamente a alternativa do lazer para os grupos de médio e alto poder aquisitivo. Caracterizam-se por serem locais capazes de atrair pessoas que se identificam entre si de alguma maneira, constituindo-se como espaços de segregação social, sobretudo no Brasil. Templos de consumo das sociedades capitalistas são cientificamente planejados, nos seus mínimos detalhes, para a supremacia da ação de comprar. Comprar mercadorias, serviços, alimentação, lazer, distinção social, segurança, o "modo americano de viver" e a ilusão de felicidade e liberdade.

Quem vai ao shopping center sabe que vai a um centro de comércio não só de bens materiais, mas que se complementa com alimentação (normalmente do tipo fast food), serviços (bancos, cabeleireiros, correios, academias de ginástica, consultórios médicos, escolas) e lazer. Ali, o consumidor de mercadorias se mistura com o consumidor de serviços e de diversão, sentindo-se protegido e moderno. Buscando fugir dos aspectos negativos dos centros das cidades, os shopping centers se propagam como locais próprios para uma melhor "qualidade de vida" por possuírem ruas cobertas, iluminadas, limpas e seguras; praças, fontes, bulevares recriados; cinemas e atrações prontas e relativamente fáceis de serem adquiridas - ao menos aos que podem pagar.

O que essa catedral das mercadorias pretende é criar um espaço urbano ideal, concentrando várias opçôes de consumo e consagrando-se como "ponto de encontro" para uma população seleta de seres "semiformados". Para transformar-se nesse novo espaço urbano, nessa cidade artificial, conta com a incorporação da imagem como elemento fundamental, principalmente no que diz respeito à persuasão e indução de comportamentos. Assim, acaba por transformar-se numa unidade simbólica de reprodução da ideologia dominante: a ideologia do capital.

Além de o shopping center ser um espaço privado que reflete a distinção entre as classes sociais torna-se um espaço onde o imprevisível, tipicamente urbano, raramente ocorre. Nos centros comerciais, não foram planejados lugares para dúvidas, incertezas ou inquietações. O "feitiço" (ou fetiche) tem sua funcionalidade no shopping center e o imaginário que se impóe parece ser o único possível: o da plenitude da vida pelo consumo e pelo enriquecimento via posse material. Nesses espaços, podemos ocupar-nos apenas dos nossos desejos - aguçados com as inúmeras possibilidades disponíveis de aquisição.

Esse mundo de sonhos que é o shopping center acaba reforçando nas pessoas uma imagem de sociedade individualista, em que os valores propagados são todos relacionados às necessidades e desejos individuais. Nesse espaço de consumo, os homens acabam sentindo que podem facilmente romper com os limites da vida coletiva e com os compromissos do convívio em grupo. O que prevalece é a vontade da posse, da distinção ou da participação em um grupo social privilegiado e, com isso, do poder individual - ainda que ilusório.

\section{SHOPPING CENTER E ENFRAQUECIMENTO DA VIDA PÚBLICA}

Este texto pretendeu desenvolver uma análise crítica do shopping center ao interpretá-lo como um símbolo da "cultura de consumo" do capitalismo atual. Sabe-se que, geralmente, a decisão de ir ao shopping center ultrapassa a necessidade de comprar algo de 
que se precisa. As pessoas buscam a felicidade por meio da materialização dos sentimentos, dos desejos e do prazer. Seus freqüentadores sentem, aparentemente, mais prazer no mundo artificial "de dentro" que no mundo real "de fora". Esta é uma dimensão onírica do shopping center, do prazer ilusório, efêmero e individualizado. Logo, pode ser visto como o espaço focalizado pelo sonho coletivo da abundância.

Essa instituição que mascara as contradições da vida social e da vida psíquica, assim como os produtos da "indústria cultural", leva a crer que a vida desumana pode e deve ser tolerada. Isso porque faz um serviço de depuração e de assepsia, mantendo apenas o "lado positivo" do mundo. É por isso que ele acaba transformando-se em atração turística de uma cidade ou passa a ser destacado como uma parte da sua formação histórica; é por isso que o shopping center ganha a dimensão que tem no inconsciente coletivo. Ele deixa de ser apenas um centro de compras e torna-se um paraíso urbano para os privilegiados. O shopping center alimenta a ilusão de que nossas insatisfaçóes psíquicas podem ser resolvidas por aquisiçôes materiais e por divertimentos reificados.

Este artigo preocupou-se em destacar que o shopping center hibrido adquire uma importância crucial para o desenvolvimento e manutenção da lógica do capital. Ele representa hoje o principal lugar da "sociedade de consumo" contribuindo para a sacralização do modo de vida consumista e estranhado, um modo de vida em que há, com a ajuda da publicidade, uma evidente predominância dos símbolos sobre a utilidade das mercadorias, do valor-de-troca sobre o valor-de-uso.

\section{REFERÊNCIAS BIBLIOGRÁFICAS}

ADORNO, T. Teoria da semicultura. São Paulo, Educação \& Sociedade, ano XVII, n.56, dez. 1996.

ANTUNES, R. Os sentidos do trabalho: ensaio sobre a afirmação e a negação do trabalho. São Paulo: Boitempo, 1999.

AUGÉ, M. Não-lugares. Introdução a uma antropologia da supermodernidade. Campinas: Papirus, 1994.

BAUDELAIRE, C. Sobre a modernidade. Rio de Janeiro: Paz e Terra, 1997. (Coleção Leitura.) BAUDRILLARD, J. A sociedade de consumo. Lisboa: Edições 70, 1995.

BENJAMIN, W. Paris, capital do século XIX. In: KOTHE, F.R. (org.), Walter Benjamin. Sociologia. São Paulo: Ática 1991. (Coleção Grandes Cientistas Sociais, 50.)

Sobre o conceito da História. In: Magia e técnica, arte e politica. Ensaios sobre literatura e história da cultura. São Paulo: Brasiliense, 1994.

FONTENELLE, I. A. O nome da marca. McDonald's, fetichismo e cultura descartável. São Paulo: Fapesp/Boitempo, 2002.

FREITAS, R. F. Centres Commerciaux: îles urbaines de la post-modernité. Paris: L'Harmattan, 1996.

FROMM, E. _. A revolução da esperança. São Paulo: Círculo do Livro, [19-].

FRÚGOLI JÚNIOR, H. Os shopping-centers de São Paulo e as formas de sociabilidade no contexto urbano. São Paulo, 1989. Dissertação (Mestrado) - Departamento de Antropologia da Universidade de São Paulo.

GAETA, A. C. Gerenciamento dos shopping centers e transformação do espaço urbano. In: PINTAUDI, S. M.; FRÚGOLI JÚNIOR, H. (Orgs.) Shopping Centers. Espaço, cultura e modernidade nas cidades brasileiras. São Paulo: Editora Unesp, 1992.
Valquíria Padilha é professora do Departamento de Administração da Faculdade de Economia, Administração e Contabilidade de Ribeirão Preto (FEA/RP) da Universidade de São Paulo. E-mail:valpadilha@fearp. usp.br

Artigo recebido em março de 2006 e aprovado para publicação em junho de 2006. 
GODELIER, M. Economie marchande, fétichisme, magie et science selon Marx dans Le Capital'. In: . Horizon, trajets marxistes en anthropologie. Paris: Maspero,

1977. v.2.

HABERMAS, J. L'espace public. Archéologie de la publicité comme dimension constitutive de la société bourgeoise. Paris: Editions Payot, 1992.

HAUG, W. F. Crítica da estética da mercadoria. São Paulo: Editora Unesp, 1997.

MARX, K. O capital. Crítica da Economia Política. São Paulo: Abril Cultural, 1983. Livro 1, t.1, v.1.

. O Capital. Rio de Janeiro: Bertrand Brasil, 1989. Livro 1, v.1.

. Grundrisse. Lineamientos fundamentales para la crítica de la economia politica

1857-1858, v.1. México: Fondo de Cultura Econômica, 1985.

MÉSZÀROS, I. Produção destrutiva e Estado capitalista. São Paulo, Cadernos Ensaio, Série Pequeno Formato, v.5, 1989.

PADILHA, V. Tempo livre e capitalismo: um par imperfeito. Campinas: Alínea, 2000.

. Publicidade e manipulação das necessidades de consumo. Petrópolis, Cultura

Vozes, ano 96, n.4, v.96, 2002.

. Shopping center: a catedral das mercadorias. São Paulo: Boitempo, 2006.

RYBCZYNSKI, W. Vida nas cidades. Expectativas urbanas no novo Mundo. Rio de Janeiro: Record, 1996.

SANTOS JÚNIOR, W. R. dos. Shopping Center: uma imagem de espelhos. In: PINTAUDI, S. M.; FRÚGOLI JÚNIOR, H. (Orgs.) Shopping Centers. Espaço, cultura e modernidade nas cidades brasileiras. São Paulo: Editora Unesp, 1992.

O Globo. Sem-teto protestam contra desigualdade social em shopping, 5.8.2000. Disponível em <http://www.globo.com.br>.

O Estado de S. Paulo. Sem-teto "invadem" shopping no Rio em protesto, 5.8.2000. Disponível em <http://www.estadao.com.br>

SENNETT, R. O declinio do homem público. As tiranias da intimidade. São Paulo: Companhia das Letras, 1998.

SILVEIRA, P. Da alienação ao fetichismo - Formas de subjetivação e de objetivação. In: SILVEIRA, P.; DORAY, B. (Orgs.) Teoria marxista da subjetividade. São Paulo: Edições Vértice, 1989. (Enciclopédia Aberta da Psique, 4.)

TASCHNER, G. B. Raízes da cultura de consumo. São Paulo, Revista USP, n.32, dez./fev. 1996-1997.

. Lazer, cultura e consumo. São Paulo, RAE - Revista de Administração de Empresas, v.40, n.4, p.38-47, out./dez. 2000.

A B S T R A C T This article analyses the shopping center's present demiurgic project from the consumption society's history, since the flanerie practices in the XIX century Paris. From its origins in the european department stores and its rapid proliferation in the post war, the shopping center is apprehended as a temple where occurs the merchandise enthronization. More than a place for shopping, it became a reified leisure place, of the desire to participate in a world of dreams sold by publicity. It is a place that excludes those who cannot consume and that also excludes, in its private logic, the citizenship, the public space, the city and its history.

K E Y W O R D S Consumption; publicity; shopping center; leisure; public space; private space. 